\title{
From SIMPAR to CIMPARC: the evolution of international pain research and management
}

This article was published in the following Dove Press journal:

Journal of Pain Research

\author{
Massimo Allegri ${ }^{1-3}$ \\ Pablo M Ingelmo ${ }^{1,4-7}$ \\ Michael E Schatman ${ }^{1,8,9}$ \\ 'Consortium of Multidisciplinary \\ Pain Researchers and Clinicians \\ (CIMPARC) Group, Milan, Italy; ${ }^{2}$ Pain \\ Therapy Service, Policlinico Monza \\ Hospital, Monza, Italy; ${ }^{3}$ talian Pain \\ Group, Milan, Italy; ${ }^{4}$ Department \\ of Anesthesia, McGill University, \\ Montreal, QC, Canada; ${ }^{5}$ Chronic Pain \\ Service, Montreal Children's Hospital, \\ Montreal, QC, Canada; 'Shriners \\ Hospital for Children, Montreal, QC, \\ Canada; ${ }^{7}$ Alan Edwards Centre for \\ Research on Pain, Montreal, QC, \\ Canada; ${ }^{8}$ Research and Network \\ Development, Boston Pain Care, \\ Waltham, MA, USA; 'Department \\ of Public Health and Community \\ Medicine, Tufts University School of \\ Medicine, Boston, MA, USA
}

Acute and chronic pain are global health problems ${ }^{1}$ with high societal costs, ${ }^{2,3}$ both in high- and low-income nations. ${ }^{4}$ As pain is best conceptualized through a multidisciplinary approach, its study should also be multidisciplinary and biopsychosocially oriented, including both basic science and clinical study/practice. Therefore, it was determined that the Study in Multidisciplinary Pain Research (SIMPAR) was needed to succeed in efforts to more effectively control pain. ${ }^{5}$

The SIMPAR concept was inaugurated 12 years ago, becoming that which we will celebrate next year in the tenth edition: a consortium of scientists and clinicians allied in their dedication to improve the treatment of pain. SIMPAR originated in Pavia, Italy, where the Scientific Head of the research hospital Policlinico San Matteo, Professor Carlo Alberto Redi, along with Professor Massimo Allegri, developed a pain research center dedicated to linking basic and translational science to clinical practice. In addition to holding a conference in Pavia, the initial conference also published the proceedings of the meeting as a supplement to the European Journal of Pain. ${ }^{6}$

The first edition's faculty discussed at great length and reached consensus that the scientific community lacked a forum in which basic scientists, clinical pain researchers, and frontline clinicians could thoroughly consider pain therapy from bench to bedside. Accordingly, each session analyzed a specific topic through three or four lectures divided into basic, translational, and clinical issues, allocating sufficient opportunity for discussion and for the conclusions of the sessions' chairpersons, who also provided clinical pearls geared toward changing day-to-day practice based upon the combination of the strongest empirical data as well as clinical observations. The organizing body decided to run two parallel courses concomitantly, with one dedicated to acute pain and the other focused on chronic pain, emphasizing the most current research findings in order to maximize the benefit of applying them to clinical practice. This approach was repeated in subsequent SIMPARs, with attendees universally voicing approval of this format.

Therefore, SIMPAR has provided the impetus to conceptualize and ultimately conduct numerous important translational clinical trials, some of which received substantial European or national grants totaling millions of euros. Furthermore, new approaches to basic research have developed as a result of SIMPAR, closing the loop from bench to bedside and back to bench again. A SIMPAR community began to network together, with members with varying interests and backgrounds joining to improve the overall quality of research by broadening its scope. This new community
Correspondence: Michael E Schatman Research and Network Development, Boston Pain Care, 85 First Avenue, Waltham, MA 0245I, USA

Tel + I 4256474880

Email Michael.Schatman@tufts.edu 
has published more than 60 peer-reviewed articles, including two sets of proceedings from SIMPAR workshops on the role of lifestyle in pain management, ${ }^{7,8}$ that have been published over the past 10 years.

SIMPAR has never strived to simply be merely another conference or society; rather, its leadership has attempted to provide a forum for education and research emphasizing the needs of those who understand that new and better solutions to pain management can be achieved only through a multidisciplinary approach to both treatment and research. SIMPAR became a multidirectional space in which to conceptualize new research questions rather than merely another event focused on the unidirectional transfer of knowledge.

Attendance to SIMPAR has grown, necessitating moving the conference from Pavia to Rome and finally to Florence in 2017. The most recent conference was held as a joint meeting with the International Symposium of Ultrasound for Regional Anesthesia and Pain Medicine (ISURA), resulting in an event attended by more than 1,000 scientists and practitioners from 34 different countries. Even at this joint conference, the philosophy remained consistent: from bench to bedside to create new clinical solutions for patients suffering from acute or chronic pain.

During the past 10 years, over 100 speakers from throughout the world have enriched this community. Attendees have discovered novel clinical and research frontiers to explore, and by avoiding the repeat of previous years' content, the conference has continued to attract return attendees from previous years as well as attracting progressively more new attendees interested in joining the community of enthusiastic clinicians, biologists, geneticists, psychologists, physiotherapists, and patients who have desired the opportunity to explore the paradigm(s) through which we can most effectively treat pain.

Despite the current academic emphasis on chronic pain, SIMPAR has also provided an opportunity for the evaluation of how acute pain may not only be managed but also effectively treated through opioid-sparing anesthesia, fast track surgery programs, and a better comprehension of all neurophysiological effects related to pain, such as immunodepression, endocrinal changes, and unresolved psychological issues. SIMPAR has come to encompass a community motivated to explore how acute pain can avoid becoming chronic through a truly multidisciplinary approach in which basic sciences are providing interesting new insights that, if confirmed, will alter our clinical practice patterns for acute pain medicine.

Despite a degree of focus on acute pain, SIMPAR has also become a community that evaluates optimal strategies for treating "the disease of chronic pain" through a multidisciplinary approach that allows us to fully comprehend all of the diverse yet interrelated facets of this global health problem, not only evaluating new techniques but additionally considering new technologies as they become available. The ultimate goal is the development and provision of personalized treatments that consider not only genetic and clinical aspects of chronic pain but also additionally apply novel technologies that further patients', as well as clinicians', comprehension regarding how to progress both the "art" and the "science" of chronic pain management.

After 10 years as SIMPAR, this community has chosen to evolve into a consortium in order to increase even further its scope of study and education, as well as to ultimately include even more scientists and practitioners who experience unsatisfactorily addressed research and practice challenges in pain management. SIMPAR has accordingly become CIMPARC (Consortium of Multidisciplinary Pain Researchers and Clinicians - www.cimparc.com), the initial edition of which will be held in northern Italy on the shores of majestic Lake Maggiore from March 14th to 16th, 2019. In order to avoid the pitfalls of growing too quickly, the first CIMPARC will be a 3-day workshop paradoxically open to only 200 attendees who believe that current paradigms for pain research and treatment can continue to improve, and that "state of the art" needs to become the rule rather than the exception in pain medicine. By keeping the initial CIMPARC small, we anticipate considerable interaction with attendees, who will be queried regarding the extent that the event meets their educational needs. Accordingly, the 2019 CIMPARC will serve as a "beta" for future editions, as we consider attendee input to be invaluable.

We hope that this brief description of the history of SIMPAR and its evolution into CIMPARC piques your interest, and that you choose to join us for what will be a truly amazing educational experience. We are confident that the size of the conference will grow rapidly, as was the case with SIMPAR. Therefore, CIMPARC 2019 will offer attendees an especially intimate opportunity to reap the benefits of what has been a uniquely intimate learning experience.

\section{Disclosure}

All of the authors of this editorial are members of the Executive Committee of CIMPARC. The authors report no other conflicts of interest in this work.

\section{References}

1. Rice AS, Smith BH, Blyth FM. Pain and the global burden of disease. Pain. 2016;157(4):791-796.

2. Blyth FM, Huckel Schneider C. Global burden of pain and global pain policy - creating a purposeful body of evidence. Pain. 2018;159(Suppl 1):S43-S48. 
3. Hoy D, March L, Brooks P, et al. The global burden of low back pain: estimates from the Global Burden of Disease 2010 study. Ann Rheum Dis. 2014;73(6):968-974.

4. Jackson T, Thomas S, Stabile V, Shotwell M, Han X, McQueen K. A systematic review and meta-analysis of the global burden of chronic pain without clear etiology in low- and middle-income countries: trends in heterogeneous data and a proposal for new assessment methods. Anesth Analg. 2016;123(3):739-748.

5. Allegri M, Clark MR, De Andrés J, Jensen TS. Acute and chronic pain: where we are and where we have to go. Minerva Anestesiol. 2012;78(2):222-235.
6. Allegri M, Clark MR, De Andrés J, et al (editors). Proceedings from the 1st San Matteo International Meeting on Pain Research (SIMPAR), October 3-4, 2008, Pavia, Italy. Eur J Pain 2008;2(1):i, 1-83.

7. De Gregori M, Muscoli C, Schatman ME, et al. Combining pain therapy with lifestyle: the role of personalized nutrition and nutritional supplements according to the SIMPAR Feed Your Destiny approach. J Pain Res. 2016;9:1179-1189.

8. De Gregori M, Belfer I, De Giorgio R, et al. Second edition of SIMPAR's "Feed Your Destiny" workshop: the role of lifestyle in improving pain management. J Pain Res. 2018;11:1627-1636.

Dove Medical Press encourages responsible, free and frank academic debate. The content of the Journal of Pain Research 'Editorial' section does not necessarily represent the views of Dove Medical Press, its officers, agents, employees, related entities or the Journal of Pain Research editors. While all reasonable steps have been taken to confirm the content of each Editorial, Dove Medical Press accepts no liability in respect of the content of any Editorial, nor is it responsible for the content and accuracy of any Editorial.

\section{Journal of Pain Research}

\section{Publish your work in this journal}

The Journal of Pain Research is an international, peer reviewed, open access, online journal that welcomes laboratory and clinical findings in the fields of pain research and the prevention and management of pain. Original research, reviews, symposium reports, hypothesis formation and commentaries are all considered for publication.

\section{Dovepress}

The manuscript management system is completely online and includes a very quick and fair peer-review system, which is all easy to use. Visit http://www.dovepress.com/testimonials.php to read real quotes from published authors. 